\title{
A CONTRIBUTION TO THE ANATOMY AND EMBRYOLOGY OF CLADORCHIS (STICHOR- CHIS) SUBTRIQUETRUS RUDOLPHI, 1814 (FISCHOEDER, 1901).
}

\author{
BY FRED D. WEIDMAN, M.D.
}

(From the Laboratory of Comparative Pathology of the Philadelphia Zoological Garden and the McManes Laboratory of Pathology, University of Pennsylvania, Philadelphia, Pa.)

\section{(With Plate V and 2 Text-figures.)}

IN 1814 Rudolphi described, under the name of Amphistomum subtriquetrum, a fluke from the caecum of the European beaver (Castor fiber). Little of importance was added for many years; i.e., until 1897, when Otto described it somewhat fully including its internal anatomy, and 1901 and 1903, when Fischoeder wrote of it in his classical revision of the Amphistomidae. In 1914 Duff described a similar parasite, this time from the American beaver (Castor fiber canadensis) which she believes to be identical with that of the European animal.

The present communication is offered in spite of the several pre-ceding descriptions, first, because all of my material was immature and hence of some value from a developmental standpoint; second, because a wax reconstruction of the internal anatomy was made, allowing enlarged representation in toto with photographic accuracy; and thirdly, because previous descriptions could be collated with mine to give a fuller description than any yet published.

My material was obtained at autopsy from the caecum of Castor fiber canadensis dying on June 9, 1913, in the Philadelphia Zoological Garden with acute haemorrhagic enteritis (P.Z.G. 2936; U.P. Path. Hist. 4366). Although a careful search was made with the aid of a fine sieve, but eleven specimens were obtained, lying in the semifluid caecal contents, close to but not attached to the mucosa, which, contrary 
to that of the small intestine, was in no way inflamed or otherwise pathologically altered. With them numerous oxyures were associated, of a species not yet determined.

The largest of the eleven specimens and a smaller were, while still moving, subjected to marked pressure between plate glass, fixed, and cleared in glycerin. The thickness of the worms thus treated permitted a determination of the grosser features only, with nothing of the minute and little of the grosser arrangement of the reproductive organs. A few ova were observed in the largest specimen which was teased with needles, the material being used in the succeeding determinations. The second, flattened specimen was cut serially in the frontal plane.

A third worm, which when entire measured $4.1 \times 2.4 \mathrm{~mm}$., was cut serially in the transverse plane. The specimens when fixed in $4 \%$ formalin were not distorted or appreciably shrunken, but the third worm was reduced by the histological technique to $2.56 \mathrm{~mm}$. in length, $2 \cdot 2 \mathrm{~mm}$. in greatest width and $2.0 \mathrm{~mm}$. in greatest ventro-dorsal diameter as measured in sections. From the histological series drawings were made with the use of the Edinger projection apparatus, and from these a reconstruction of the internal anatomy was made by the wax plate method, omitting only the intricately formed structures such as vitellaria, nervous system and excretory ducts. All measurements hereafter given, unless otherwise noted, are taken from this third (shrunken) worm.

\section{External Anatomy.}

The specimens measure $5 \cdot 1-6.3 \mathrm{~mm}$. long $\times 3.0-3.5 \mathrm{~mm}$. broad and $2 \cdot 0-2 \cdot 25 \mathrm{~mm}$. dorso-ventrally. They are subcylindrical, the greatest diameter lying at the anterior borders of the acetabulum.

The posterior extremity is broadly rounded and moderately curved ventrally. The anterior extremity is more strongly directed ventrally so that the oral orifice points ventrally. The anterior extremity is broadly rounded and variably but never more than moderately attenuated, from which circumstance some specimens are pyriform and others subcylindrical. One specimen is exceptional; its anterior extremity tapers more than in any of the others and is recurved upon the body axis in the form of an inverted question mark. The margins of all are rounded and undefined; the dorsum is broadly convex, the caeca being often seen in fixed specimens with the naked eye and always with a hand-lens. The caeca appear as black bilateral areas posteriorly and dorsally and are sometimes traceable upwards to the 
equator. The venter is flat transversely in its mesial portion, curved laterally, and strongly curved longitudinally. When fresh, the worms were pinkish grey and showed slight vermicular movement upon gentle warming; the movements were most marked in the anterior extremity and probably were responsible for the variations in the degree of attenuation noted in fixed specimens. When fixed in formalin they are of a grey green colour.

The oral orifice is terminal, directed ventrally, small, circular, unarmed, without papillae or other specializations, and measures $0.25 \mathrm{~mm}$. in diameter. The genital pore lies $1.15 \mathrm{~mm} .^{1}$ posterior to it, is circular, measures $0.1 \mathrm{~mm}$. in diameter and carries a low broad papilla in the depths of the very small atrium into which it leads. I could not find a suctorial muscle around it other than the continuation of the general body muscles. Otto and Duff state that there is a suctorial muscle, but my examination of Duff's material strengthens me in the belief that there is no such muscle. Fischoeder, moreover, states that there is none. The centre of the acetabular orifice is $3.0 \mathrm{~mm}$. posterior to the genital pore and $1.8 \mathrm{~mm} .{ }^{1}$ from the posterior extremity. Its orifice is large $(0.70 \mathrm{~mm}$. in diameter), circular, and tilted obliquely ventrally.

The triangular form, due to dorsal ridging, originally ascribed to the worm by Rudolphi, could doubtfully be made out microscopically in the specimens at hand and not at all grossly. The histological cross sections vary in form at different levels, but are never fairly subtriangular. Anteriorly they are subcircular, with an inconstant gentle dorsal depression at the right of the mid-line. This shortly disappears, the intercaecal portion of the dorsum becoming flat, and at the level of the genital pore strongly concave. Below this point the venter in turn becomes markedly flattened and now a gentle median dorsal swelling appears, to disappear at the anterior border of the acetabulum. Between the genital pore and the latter level the transverse diameter of the worm is to the dorso-ventral as $3: 2$. The venter between the acetabular orifice and the anterior acetabular margin is now strongly concave (obliquity of plane of section due to tilting of acetabulum). At the level of the acetabular orifice the venter resumes its convexity (and maintains it to the terminus) the section here appearing subcircular with flat or concave dorsum. Below this level a distinct median dorsal swelling appears, which continues a short distance $(0.2 \mathrm{~mm}$.), disappears for a distance of $0.064 \mathrm{~mm}$. to re-appear for a second $(0.2 \mathrm{~mm}$.) course. After this one of the declivities gradually disappears, the other forming

1 Measurements taken from the entire specimen $5.95 \mathrm{~mm}$. Iong. 
one side of a cleft which indents the worm fairly deeply. The cleft gradually becomes shallower, finally disappearing toward the posterior extremity.

From the above description it will be seen that the dorsal ridge of Rudolphi (1814) is represented in the specimen here studied by a short, low, rounded median discontinuous ridge extending $0.4 \mathrm{~mm}$. over the dorsum of the worm, i e. only about one-sixth of its length. To the writer it seems to be a very inconspicuous character on which to name the species.

The surface is smooth and glistening except near the genital pore, where the cuticle is thrown into deep transverse ridges. There are no spines, tubercles or ridges anywhere.

The acetabulum is large, subterminal, tilted obliquely ventrally, and measures $1.45 \mathrm{~mm}$. laterally, $1.0 \mathrm{~mm}$. dorso-ventrally and $0.92 \mathrm{~mm}$. antero-posteriorly.

The cuticle agrees in general structure with that of other trematodes; it shows no spines or other specializations. Duff discusses the subcuticular cells and their function with considerable detail; she considers the "large cells" in the suctorial muscles as embryonic remnants rather than nervous elements.

\section{The Alimentary System.}

The oral orifice leads into a roomy oral cavity of subglobular shape measuring $0.6 \mathrm{~mm}$. in width, $0.22 \mathrm{~mm}$. dorso-ventrally and $0.384 \mathrm{~mm}$. antero-posteriorly. From its postero-lateral portion, two blind tubular evaginations, one on each side and each $0.2 \mathrm{~mm}$. long, extend into, but not through, the muscle of the oral sucker. Fischoeder takes issue with Otto here. The former found the oral cavity very small, of triangular shape in cross section with one angle directed ventrally and the two pockets springing from the other two angles. The latter describes the cavity as a cleft (Spaltförmig). It seems possible that the variation might depend upon different degrees of rigor mortis in the oral suctorial muscle or to the kind of preservative used. The oral cavity is surrounded by a muscle $0.25 \mathrm{~mm}$. thick in the form of a much flattened sphere measuring $1.1 \mathrm{~mm}$. dorso-ventrally, $1.1 \mathrm{~mm}$. in width and $0.9 \mathrm{~mm}$. antero-posteriorly. At its most anterior portion its fibres are arranged into two closely placed sphincters, the more anterior being the heavier. They do not lie at the oral orifice, but well (fully $0.25 \mathrm{~mm}$.) internal thereto. The beginning of the oral cavity thus assumes a broad, short, tubular form lined by cuticle and not surrounded by special muscle. 
The oesophagus passes from the centre of the posterior portion of the oral cavity, is very short, simple, and surrounded by a heavy muscular coat, a continuation of the muscle of the oral sucker, together with large and numerous so-called salivary cells. In addition, a notable sphincter is present at the oesophago-oral junction; this muscle has been commonly missed by other writers. The oesophageal muscle continues over the bifurcation to include both arms of the caeca, accompanied laterally by cuticle and subcuticular cells, but no "salivary" ones. Here again there has been no agreement among writers. Otto is very positive about an oesophageal muscle being present while Duff and Fischoeder are silent about it. The caeca are broad, not branched, lightly sinuous and pass at once to the lateral borders which they follow posteriorly, each caecum ending blindly behind the acetabulum close to cuticle. The caeca contain black granular material and vegetable cells, they are notably constricted in places, forming sacculations above and below, one so large as to closely approach the size of the oral sucker. Upon reaching the acetabulum the caeca pierce the vitellaria which lie close to the cuticle, shortly emerging close to the cuticle with vitelline follicles still present mesially but not laterally.

\section{The Reproductive System.}

The male organs. The testes are preequatorial, preacetabular, lie ventral to and between the caeca and antero-posteriorly to each other, the anterior but slightly to the right and but slightly ventral to the posterior. The posterior border of the hind testis lies slightly posterior to the equator, reaches almost to the acetabulum and one or two of its branches extend slightly below the level of the anterior acetabular border. The anterior border of the anterior testis extends well forward beyond the ventral border of the oral sucker. Each consists of an irregular, small body from which six to eight long, wavy, coarse, tube-like branches extend. They are mostly bifid and extend in all directions; a few occur ventrally, whilst by far the greatest number extend dorsally between the caeca. The branches thus come to overlap the neighbouring testis, while their fields ${ }^{1}$ overlap and almost coincide. On account of their branching character their whole mass is difficult to estimate, but it is about equal to that of the oral sucker and certainly much less than that of the acetabulum. Spermatozoa were numerous in the body and branches of the testes in both worms that were sectioned.

${ }^{1}$ Nomenclature advocated by Stiles. 
In the second yet more immature specimen (the one sectioned longitudinally and which had been compressed) the testes appear differently. They are elongated dorso-ventrally and well separated from each other, the dorsal halves of each are quite smooth, branches projecting radially from the ventral portions only. The branches are short and comparatively straight, and the anterior testis lies distinctly ventral to the posterior one.

The right vas efferens originates in the anterior testis (which is therefore the right testis), emerging from the right side of the base of a heavy dorsal branch. It curves posteriorly for a very short distance $(0.112 \mathrm{~mm}$.$) , and, at the level of the genital pore arches anteriorly and$ laterally, gaining the mesial wall of the right caecum; hugging this closely, it passes anteriorly and slightly dorsally but always intercaecally. The left vas efferens emerges from the body of the inferior testis, posteriorly and slightly to the left of the mid-line and approximately mid-way between its anterior and posterior borders. It passes anteriorly and slightly dorsally being surrounded at first by testicular branches, but soon it attains and follows the caecum like its fellow. The two caeca converge rather quickly post-bifurcally and unite well dorsally immediately anterior to the most anterior testicular branch. The vas deferens is short, and not provided with musculature; it quickly bends ventrally and posteriorly (accompanied at this point by the uterus) forming a moderately (at one point only notably) dilated and closely coiled vesicula seminalis externa. The latter pierces a pyriform cirrus pouch lying slightly to the left of the median line, anterior to the genital pore, and immediately anterior to the posterior border of the oral sucker. Its long axis extends obliquely from a left, anterior and dorsal point toward the right, posteriorly and ventrally, its broader extremity directed dorsally; it measures $0.3 \mathrm{~mm}$. in length, $0.18 \mathrm{~mm}$. wide, and its walls are moderately thick, $0.02 \mathrm{~mm}$. They taper finely at the end which encloses the cirrus. The vesicula seminalis interna makes one or two close turns, becomes very narrow and continuous with the short poorly developed cirrus ${ }^{1}$. The interval between the coils and the cirrus wall is occupied by a fine reticulum holding numerous (prostatic?) cells. The tip of the penis occupies a chamber which passes into a very fine ejaculatory duct, that unites in the genital papilla with the metraterm. Spermatozoa were not found anywhere in the tubular portions of this system.

Variations from the foregoing were noted as follows in the more

1 Otto does not note the cirrus. 
immature specimen which was sectioned longitudinally. First, the wall of the cirrus pouch thinned so rapidly toward the narrower extremity that it was quite lacking before the cirrus was reached. Second, the chamber holding the cirrus was contracted to very small dimensions, and quickly narrowed to a fine tube.

Duff (p. 89), describes the testes as lobed, and so figures them in Fig. 1. In Fig. 4, however, she shows sections of branches, and my study of her microscopic preparations shows that they are really branched, as in my own material.

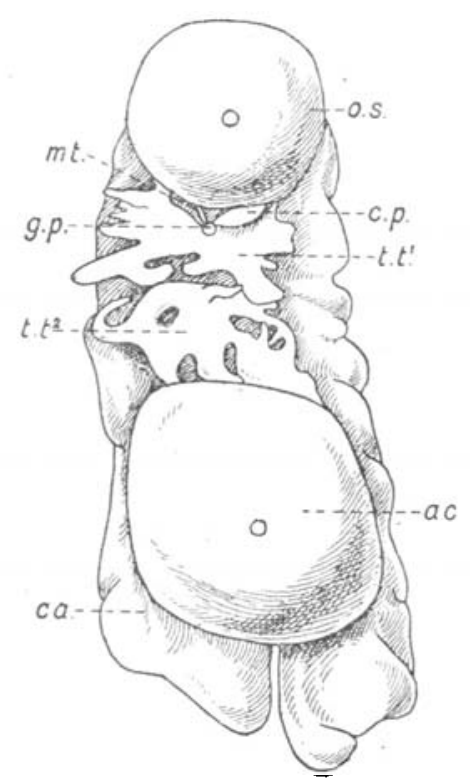

Fig. 1. Drawing from photograph of wax reconstruction of internal anatomy. Ventral view : 0.8 . oral sucker; m.t. metraterm; g.p. genital papilla; $c . p$ cirrus pouch; t.t. ${ }^{1}$ anterior testis: t.t. $^{2}$ posterior testis; ac. acetabulum; $c a$. caeca.

The female organs. The ovary is median or sub-median, dorsal, and contiguous to the anterior portion of the acetabulum. Its zone does not extend anterior to the acetabular zone. It is subspherical, appears subtriangular posteriorly in cross section and subquadrilateral anteriorly; it measures $0.224 \times 0.25 \mathrm{~mm}$. and $0.35 \mathrm{~mm}$. dorso-ventrally. The oviduct passes from its dorsal aspect approximately mesially and extends a short distance dorsally and posteriorly, where it effects a junction with Laurer's canal, dorsal and close to the shell gland in the median line. It then makes three or four easy turns in this region and 
at once pierces the shell gland, becoming continuous with the much broader oötype. The shell gland is median, posterior to the ovary, and contiguous to the acetabulum; it measures $0.184 \times 0.21 \mathrm{~mm}$. and $0.220 \mathrm{~mm}$. dorso-ventrally; it is irregular in shape, deeply indented sinistro-ventrally by the oötype and is suddenly attenuated posteriorly and anteriorly, the latter process extending well to the right and slightly overlapping the ovary. The oötype lies embedded between the shell gland dorsally and the acetabulum ventrally, slightly to the left of the median line; within it there is a finely granular and reticular blue material (sections stained by haematoxylin and eosin) female germ cells, vitelline granules and spermatozoa; it measures $0.07 \mathrm{~mm}$. broad, $0.14 \mathrm{~mm}$. long and has very thin walls. Laurer's canal begins at about the mid-point of the oviduct as above described, it follows the latter closely anteriorly, extending directly to the ovary where it suddenly bends dorsally, makes one or two easy spirals and ends dorso-median at the level of the origin of the oviduct and $0.448 \mathrm{~mm}$. anterior to the excretory pore. It does not cross the excretory vesicle or duct and is not provided with a receptaculum seminis.

The uterus passes from the left side of the oötype, in contact with the dorsum of the acetabulum and slightly left of the median line; it coils intricately in this region, passing anteriorly and dorsally to the ovary, showing its closest turns in this region; it now passes anteriorly with a few easy turns in the dorsum of the worm, dipping ventrally once between the testicular branches and the caeca on either side. Just above the level of the cirrus pouch it turns sharply ventrally and arches over the anterior testis; here it runs closely parallel to the vas deferens, lying to the left of the same; it passes now slightly posteriorly and ventrally to the right side of the cirrus pouch, uniting with the ejaculatory duct to form the hermaphroditic canal. This is very fine and lies in a broad, low genital papilla situated in a single genital atrium. The genital pore shows no trace of a sphincter, much less a sucker.

At numerous positions, and in practically all parts of its course, the uterus dilates into aneurysm-like structures three to eight times the diameter of the rest of the tube. Here the cuboidal epithelium is replaced by a flat squamous type and the lumen contains a blue granular material, sometimes a few pink (vitelline) granules or vitelline cells and occasionally a primitive germ cell. Nowhere are fully developed ova found, from which it follows that the specimen described was immature. This absence of ova, or at most the presence of but a solitary undeveloped one, is opposed to the view of Otto who believed that the 
thinner portions of the uterus were due to the internal pressure of the ova. It would appear from the findings here that the sacs are developmental features, and of hereditary rather than acquired nature. Additional weight is lent to this view by the occurrence of one or two places of thinning which are not distended. Spermatozoa were not found in this tube except close to the oötype.

The vitellaria consist of two roughly triangular structures occupying the posterior two-thirds of the worm; the broader side of each triangle is convex and follows the body margin; the other two sides are concave, and their angle of junction is directed toward the ovary. The vitellaria consist of very small sparse follicles containing minute quantities of pink granules; as already stated above, each mass is pierced by the caecum. The courses of the ducts are not surely made out either in their transverse or longitudinal portions. In the specimen here studied a vitelline reservoir is easily made out close to the shell gland and to the right of the same, but a communication with the genital tube on the one hand, or with the vitellaria on the other, could not be established. Other writers disagree upon the arrangement of the terminal vitelline apparatus; Otto states that two transverse ducts form a common longitudinal one which enlarges posteriorly to reservoir proportions, that it then narrows markedly and unites with the genital tube shortly posterior to the point where it is joined by Laurer's canal; Fischoeder describes the vitellaria as emptying into a paired, distinct reservoir, but does not state the manner of its communication with the genital tube. The extent of the vitellaria farther forwards is a little different in this specimen from what has been described by other authors. Otto limits the vitellaria to the posterior third, and other writers to the posterior half. The vitellaria were especially sparse in the specimen cut longitudinally. The obscurity of these ducts is probably explained by the immaturity of the specimens.

The ova teased from the uterus of the largest specimen are oval, not operculated, and measure $0.13-0.15 \times 0.085-0.09 \mathrm{~mm}$.

\section{The Muscular System.}

Apart from the features which have already been noted, the suckers do not vary from the plan usually found in other Amphistomidae. The subcuticular musculature varies in one respect, i.e. the bundles occurring over the venter are much more robust than those of the margin and dorsum. The increase in their size here is so marked as to seem scarcely 
due to contraction (in production of body flexion), such as I have seen in Fasciola hepaticum and Fasciolopsis buski.

\section{The Excretory System.}

Fine channels lead to the posterior end of the specimen, where there is a small excretory vesicle. The latter begins below toward the tip of the caeca, $0.288 \mathrm{~mm}$. from the body extremity, as two long, tubular, bilateral spaces lying closer to the cuticle than to the acetabulum. They unite at the level of the excretory pore and continue anteriorly as one vesicle, which, in the specimen studied, was of irregular shape, and apposed to the acetabulum. Here it attains its greatest size, at most but little larger in bulk than the ovary, and gradually narrows anteriorly to disappear at the level of the oötype. Its duct takes origin from the dorsum of the vesicle at its broadest part, anterior to its bifurcation, and passes posteriorly dorsal to the vesicle, ending dorso-median at the level of the acetabular orifice and $2 \cdot 2 \mathrm{~mm}$. from the posterior extremity. The anterior portion of the vesicle is lined by a very tall columnar "epithelium," apparently the most highly specialized "epithelial" cell in the worm; this lining is continued posteriorly over the dorsum of the vesicle until the internal ductal orifice is reached, into which it passes for a short distance. Coarse pink hyaline droplets appear to exude from it into the vesicle. Duff states that it is surrounded by thick spongy muscular walls.

\section{The Nervous System.}

The course of nerve fibres and the localization of the ganglia could not be determined in my material, but other authors agree in describing a ring of perioesophageal ganglia from which three nerve trunks extend on each side anteriorly and one on each side posteriorly with commissural fibres between the posterior trunks. Finer fibres are distributed from the commissures and trunks to the reproductive and excretory organs,

\section{Systematic Position.}

The full diagnosis of the systematic units concerned are available in the works of Fischoeder and of Stiles and Goldberger, for which reason their names only will be given here, as follows: Superfamily PARAMPHISTOMOIDEA; Family Paramphistomidae; Subfamily Cladorchinae; Genus Cladorchis; Subgenus Stichorchis. Its important special features are, in brief, the presence of: a cirrus pouch, two pharyngeal diverticula, a two-ringed pharyngeal sphincter and branched 
(klados, a branch) testes lying one above (stichos) the other. With the exception of the new superfamily, the above classification follows that given by Fischoeder. Reference to Stiles and Goldberger's work will show that this new high unit is a justifiable one (p. 15) but that my material will not fit in with their lower rank diagnosis (pp. 169 and 170) of Cladorchis and Stichorchis largely on account of the question of musculature of the genital atrium. Dr Stiles informs me that he would be inclined to separate this beaver fluke from both Cladorchis and Stichorchis and make it the type of a new genus on the basis of this lack of a genital amolrar Thio wruld sortainly be necessary to

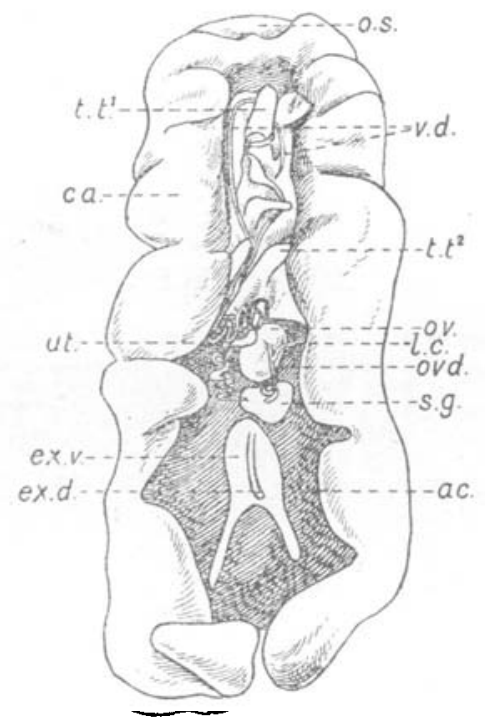

Fig. 2. Drawing from photograph of wax reconstruction of internal anatomy. Dorsal view : o.s. oral sucker; v.d. vas deferens; $t_{\text {.t. }}{ }^{1}$ anterior testis; $t$. t. $^{2}$ posterior testis; ca. caeca ; ov. ovary; ut. uterus; ovd. oviduct; s.g. shell gland; ex.v. excretory vesicle; ex.d. excretory duct; ac. acetabulum; l.e. Laurer's canal.

accommodate it to Stiles and Goldberger's classification. I feel personally that the several lots of material should be collected and reviewed before reaching a final conclusion, paying special attention to (1) whether the genital atrium is or is not musculated, (2) the oesophagus musculated or not (Otto says it is musculated in the Amphistomidae in general), (3) presence of cirrus, (4) general anatomy of vitelline system, (5) oesophageal sphincter.

This paper contributes perhaps more to the subject of the development than to that of the anatomy of this fluke. In respect to the 
anatomy emphasis is laid on certain individual features which have not been generally recognized although they have been pointed out by some writers. These features are: the pre-oesophageal sphincter; oesophageal musculature and heavy ventral subcuticular musculature. From the point of view of development the minor branching of the testes has been noted by other authors and it has been assumed that the testes become more complex with maturity. Previous writers make no reference to vitelline development. That this development occurs at a late stage is best shown by reference to my second specimen (Fig. 2) wherein but a few follicles are noted; the late development may explain why the ducts could not be traced in my material.

The absence of any inflammatory changes near the fluke, and the good nutritional condition of the host indicate that the worm is a commensal parasite, this impression being strengthened by observance of vegetable fibres in its caeca.

\section{REFERENCES}

1814: Amphist. subtriquetrum. Rudolphi, Mag. f. d. n. Entdeck. in. d. ges. Naturk. Berl. (Apr.-Juni 1812), v. 6, 2. Quartal, pp. 83-113 in Castor fiber, Berlin, May. 1897: Amphist. subtriquetrum. Otto, Deutsche Ztschr. f. Thiermed. u. vergl. Path., xxI. p. 105.

1901: Cladorchis (Stichorchis) subtriquetrus. Fischoeder, Zool. Anz., Leipz. v. 24, 24 June 1901, p. 373.

1903: Cladorchis (Stichorchis) subtriquetrus. Fischoeder, Zool. Jahrh., Jena, Abt. f. Syst., v. 17 (4-6), 9 Feb., p. 494.

1910: Cladorchis. Stiles and Goldberger, Hygienic Laboratory Bulletin, No. 60, Washington, D.C.

1914: Amphistomum subtriquetrum. Duff, Trans. Royal Soc. of Canada, Sept. 1914, Series III. Vol. vIII. p. 87.

For full bibliography see Index Catalogue of Medical and Veterinary Zoology, Washington, D.C. Bulletin, No. 37, 1908, p. 96.

\section{DESCRIPTION OF PLATE $V$.}

Fig. 1. Longitudinal section through immature, artificially flattened specimen (no. 2). $s p h$. oral sphincter; $0 . s$. oral sucker; oe. oesophagus; $c a$. caeca ; ov. ovary; a.t. anterior testis; p.t. posterior testis; $v . d$. vas deferens; $u t$. uterus; ac. acetabulum. The testes are sectioned through their dorsal halves. Note their lack of branching in this immature specimen.

Fig. 2. Transverse section at junction of second and third body fifths through posterior testis. t.bod. body of testis; t.br. testicular branches; ca. caeca; ut. uterus; vit. vitelline follicles. Compare robustness of ventral and dorsal cuticular muscles. 

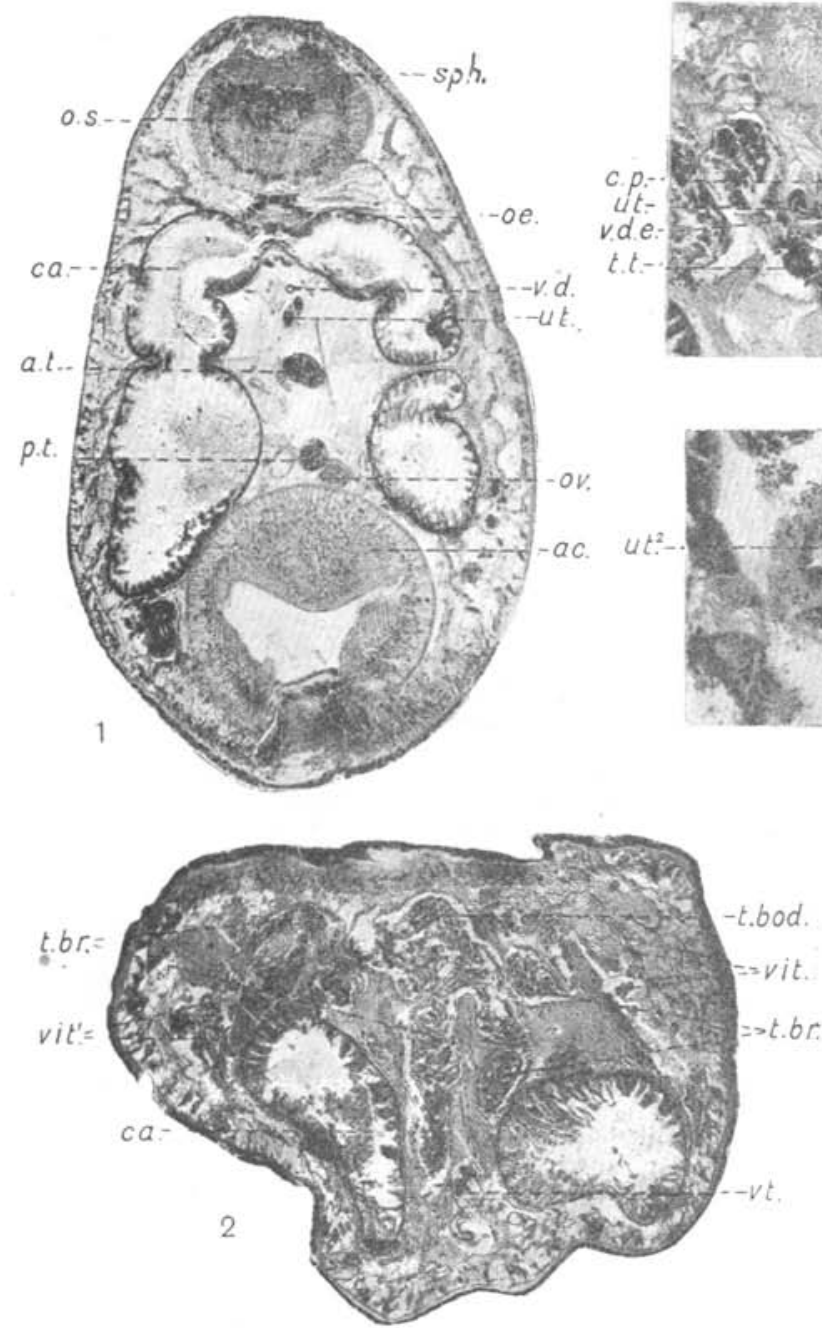

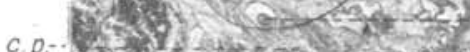

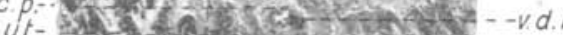

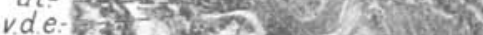

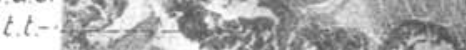
1. $x \times 3$ ?

4
$-0 . s$

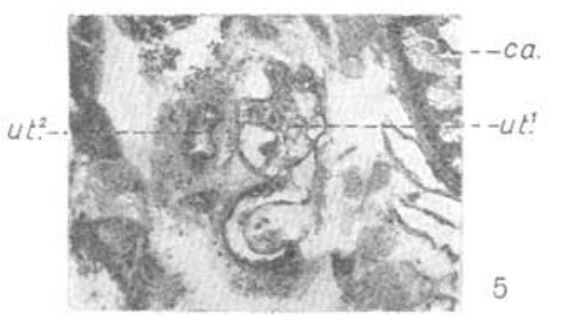

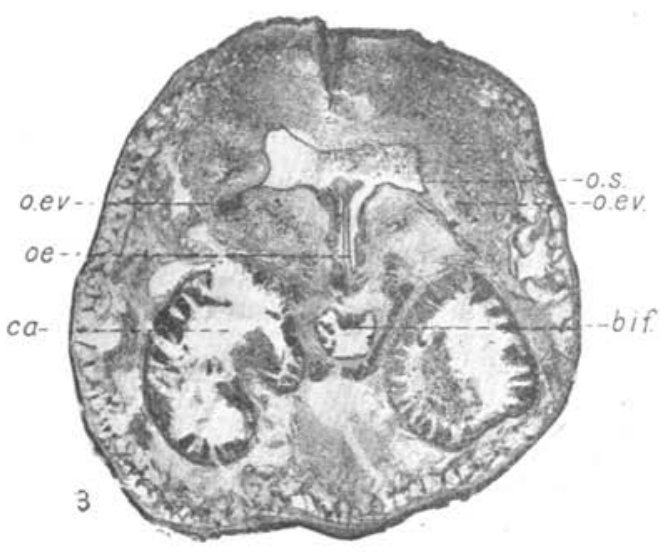
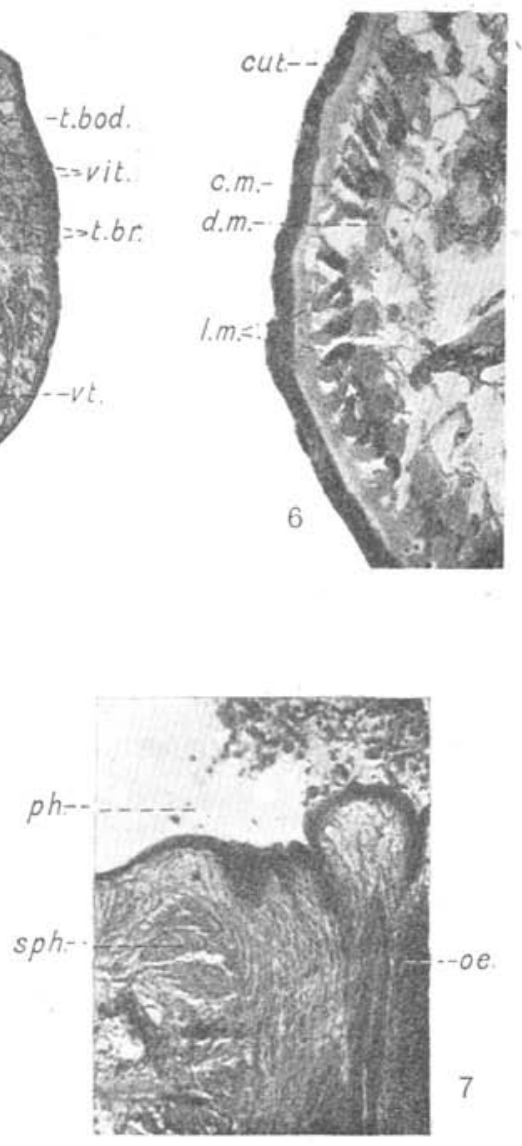
Fig. 3. Transverse section to show oral evaginations and muscular character of oesophagus. o.er. oral evagination; o.s. oral sucker; oe. oesophagus; ca. caeca; bif. bifurcation of oesophagus.

Fig. 4. Transverse section immediately posterior to oral sucker. o.s. oral sucker; c.p. cirrus pouch; ci. cirrus; t.t. testicular branches; v.d.i. vas deferens interna; $u t$. uterus; v.d.e. vas deferens externa; $c a$. caeca.

Fig. 5. Transverse section cut close to Fig. 2, more highly magnified. Note absence of ova in uterine dilatations. The reticular material therein stains faintly blue with haematoxylin and eosin. $c a$. caeca; $u t .^{1}$ dilatation of uterus; $u t .^{2}$ non-dilated part.

Fig. 6. Transverse section through portion of ventral body wall, crit. cuticle; c.m. circular muscle; d.m. diagonal muscle; l.m. longitudinal muscle.

Fig. 7. Transverse section through oesophagus cut close to Fig. 3 and more highly magnified, $s p h$. oesophageal sphincter; oe. oesophagus; $p h$. pharynx. 